\title{
Assessment of motor development using the Alberta Infant Motor Scale in full-term infants
}

\author{
Büşra Kepenek-Varol ${ }^{1 \oplus}$, Zeynep Hoşbay², Selçuk Varol ${ }^{3}$, Emel Torun ${ }^{4}$ \\ ${ }^{1}$ Department of Physiotherapy and Rehabilitation, Faculty of Health Sciences, Nuh Naci Yazgan University, Kayseri; ${ }^{2}$ Department of \\ Physiotherapy and Rehabilitation, Faculty of Health Sciences, Biruni University, İstanbul; ${ }^{3}$ Department of Pediatrics, Yeşilhisar State \\ Hospital, Kayseri; ${ }^{4}$ Department of Pediatrics, Bezmialem Vakif University Medical Faculty, İstanbul, Turkey.
}

\begin{abstract}
The Alberta Infant Motor Scale (AIMS) is a well-known, norm-referenced scale that evaluates the gross motor development of children from birth to 18 months. The aim of the study was to compare the Canadian norms with the AIMS scores of a Turkish sample of infants, and to investigate whether the current reference values of the AIMS are representative for Turkish full-term infants. The study was conducted with 411 Turkish infants of both sexes (195 girls and 216 boys), born with gestational age 38 weeks and older, weighing $\geq 2500 \mathrm{~g}$ at birth. Motor performance of all the cases at different ages were assessed with the AIMS which was used by a physiotherapist. The mean AIMS scores of Turkish infants were compared with the norm values of the original AIMS established in a Canadian sample of infants. The results showed no statistically significant differences between the AIMS scores of Turkish and Canadian infants during the first 18 months of life except at $0-<1$ and $2-<3$ months of age. The AIMS scores were significantly lower in Turkish infants than in Canadian infants at $0-<1$ $(\mathrm{p}=0.025)$ and $2-<3(\mathrm{p}=0.042)$ months of age. In conclusion, the AIMS can be used in Turkish children to assess gross motor development, especially after 4 months of age. However, this paper was presented as a preliminary study to compare AIMS results between Turkish and Canadian infants, and further studies are needed to realize the Turkish validation of AIMS.
\end{abstract}

Key words: Alberta Infant Motor Scale, infants, motor development, motor skills.

Early detection of developmental delay in children, especially at $0-2$ years of age, is important in terms of allowing early intervention. Motor development assessment is generally performed in the detection of delays and monitoring the achievement of new skills. Clinicians interested in early intervention such as doctors, physiotherapists, and occupational therapists are involved in assessing the motor status of infants, and usually use standardized neuromotor assessment instruments to help make decisions about a child's motor development. ${ }^{1}$ Appropriate evaluations are necessary to identify motor developments and there are a number of tools available

$\triangle$ Büşra Kepenek-Varol

busrakepenek@gmail.com

Received 18th January 2019; revised 22nd February 2019, 11th March 2019; accepted 21st March 2019 for physicians to use such as The General Movements Assessment, ${ }^{2}$ Test of Infant Motor Performance, ${ }^{3}$ The Bayley Scale of Infant and Toddler Development (especially the third edition, Bayley-III) ${ }^{4}$ and the Alberta Infant Motor Scale (AIMS), 3,5,6 which are commonly used. The General Movement Assessment is an example method to assess infants up to 5-6 months and the predictive value of the assessment is high, especially between 2 and 4 months of age. ${ }^{2}$ The Test of Infant Motor Performance is also a predictive tool to evaluate motor performance of infants under 4 months of age. ${ }^{3}$ Bayley-III evaluates the gross motor development of infants and young children, and the fine motor skills, cognitive ability, language skills, and social-emotional behaviors up to 42 months of age. ${ }^{4}$ The AIMS is a frequently used tool to evaluate the gross motor development of children in the early stage of life. ${ }^{1,5}$ 
AIMS is a norm-referenced scale that evaluates the gross motor development of children from birth to 18 months. The scale was developed by Piper and Darrah ${ }^{5,7}$ in Alberta, Canada, and reference values were established in a Canadian sample of infants. The scale allows the evaluation of gross motor function development of children, identifying children in need of early intervention, and monitoring treatment programs. The clinical application of AIMS is simple, the spontaneous movements of the child are evaluated by observation, and the test can be completed in a short time..$^{5,8}$

AIMS has been used internationally as a clinical or research outcome measure for assessing gross motor abilities of term or preterm infants, although it is a Canadian norm-references measure. ${ }^{9-13}$ The validity of the AIMS was obtained for infants in Spain, ${ }^{12}$ a South African region, ${ }^{14}$ Brazil,,${ }^{15}$ Japan, ${ }^{16}$ China, ${ }^{17}$ and Taiwan. ${ }^{18}$ Although AIMS is commonly used in various countries, the question remains as to whether current Canadian norm values represent the AIMS scores of infants with different cultural backgrounds. ${ }^{11,19,20}$ In the literature, it has been reported that Brazilian children, ${ }^{11}$ Dutch children, ${ }^{21}$ and Flemish infants ${ }^{22}$ showed differences in motor performance assessed by the AIMS compared with Canadian norm values, and it has been recommended that new reference values should be established for the AIMS of infants in other contries. ${ }^{11,21,22}$ However, in another study performed by Syrengelas et al. ${ }^{13}$, the motor performance and AIMS scores in full-term Greek children were similar to Canadian norms. In addition, Darrah et al. $^{20}$, who developed AIMS, demonstrated that AIMS continued to perform remarkably similarly to previous studies, the current normative values had remained valid for over a 20 years, and it might not be necessery to investigate ethnic or international differences. However, Saccani et al. ${ }^{11}$ reported that the AIMS scores of Brazilian infants were lower than the scores of Canadian norms, ${ }^{5}$ and the authors emphasized that to establish reference values for the AIMS of infants was important across cultures. AIMS has been widely used as a measure of clinical outcome and research worldwide, ${ }^{9,10,13,18}$ including Turkey. ${ }^{23,24}$ To our knowledge, no study has investigated AIMS reference values in Turkish infants. The aim of this study was to compare the Canadian norms with the AIMS scores of a Turkish sample of infants, and to investigate whether the current reference values of AIMS were representative for Turkish full-term infants during the first 18 months of age.

\section{Material and Methods}

\section{Subjects}

A total of 411 healthy full-term infants aged between 5 days and 18 months were assessed using AIMS. The study was conducted with Turkish infants of both sexes, born with gestational age 38 weeks and older, and weighing $\geq 2500 \mathrm{~g}$ at birth. The total sample consisted of 195 girls and 216 boys. The age and sex distribution per month of age is shown in Table I. The exclusion criteria consisted of infants with a history of pre-, peri- or post-natal problems associated with risk for developmental delay, congenital malformations, orthopedic or neurologic diseases, genetic syndromes, and status of the child that would not allow for assessment (such as crying, restlessness, acute or chronic disease). No infants were assessed more than once. Parents were informed about the aim of the study and informed consents

Table I. Demographic and clinical characteristics of infants.

\begin{tabular}{lc}
\hline Characteristics & Results \\
\hline Gender, $\mathrm{n}$ & \\
$\quad$ Girls & 195 \\
$\quad$ Boys & 216 \\
Gestational age (week), mean \pm SD & $39.1 \pm 1.08$ \\
Birth weight (g), mean \pm SD & $3301.4 \pm 475.3$ \\
Type of birth, $\mathrm{n}$ & \\
$\quad$ Vaginal & 187 \\
$\quad$ Cesarean section & 224 \\
\hline
\end{tabular}

$\mathrm{n}=$ number of participants, $\mathrm{SD}=$ standard deviation 
were received. The study was aproved by the Medical Ethics Committee of Bezmialem Vakıf University, Turkey (54022451-050.05.04-16/191).

\section{Assessment tool and procedure}

AIMS is a well-known, norm-referenced, discriminative tool used to evaluate gross motor development in early infancy. It can be performed by any health professional with a background in infant motor development and an understanding of the main components of movements. AIMS is a measure of gross motor development based on dynamic motor theory and neuromaturational theory. It was developed by Canadian physiotherapists, and the normative values were established using a cohort of 2202 Canadian infants. ${ }^{5}$ The scale comprises 58 items that assess the spontaneous movements of infants in the prone (21 items), supine (9 items), sitting (12 items), and standing (16 items) positions. Items are defined that detail weight-bearing ability, postural alignment, and the control of antigravity muscles during observation of motor skills of the infants..$^{5-7}$ The least and most observed items in each position are defined as a 'window' of current motor development. AIMS is graded on a score sheet as observed items (one point) or not observed (zero point) within this window; a manual is available to provide more details on scoring movements. The total raw score is the sum of the scores for the four positions, which can range between 0 to 58; higher scores indicate better motor development. The total raw score is converted to an age-based percentile rank, varying from 5 to $90 \%$ for comparison norms from a sample of Canadian infants. ${ }^{5}$ The validity and reliability of AIMS has been demonstrated. ${ }^{6,12,18,25}$ AIMS has many advantages such as easy evaluation through observation, it is noninvasive, inexpensive, requires minimal space, it can be applied quickly (approximately 20-30 minutes), and does not require excessive handling of the child..$^{5,6}$

The children were properly examined by an expert pediatrician before evaluating with AIMS, and then directed to the physiotherapist in accordance with the inclusion criteria. All 411 infants at different ages were assessed once using AIMS. AIMS was used by a physiotherapist who had more than 8 years' experience in pediatric physiotherapy (especially in evaluation and treatment of infants), and had used AIMS extensively. AIMS was applied in a quiet room with adequate space and toys required for the assessment, and adjustable room temperature. The child was underdressed or dressed lightly and observed in the evaluation room in the presence of the mother or father or both, and he/she was active and awake during the assessment. Toys were used to encourage and prompt some children to move to different positions. The AIMS assessment took approximately 25 minutes per infant, including waiting for the infant to adjust to the surroundings. At the end of the test, the total raw score was calculated and the percentile ranks were established. All assessments were performed by the same physiotherapist, and the scale was performed at each month of age.

\section{Data analyses}

Statistical analyses were performed using SPSS version 20 for Windows. The quantitative variables were presented as means with standard deviations. In this study, there were 18 groups according to the age of the children. The G*Power v3.1 program (Universitat Kiel, Germany $)^{26}$ was used to calculate the sample size on the basis of findings from a previous study, ${ }^{13}$ which revealed that at least 20 children for each age group could provide a power of $80 \%$. The mean AIMS scores, standard deviations, and percentiles were calculated for each group. The one-sample t-test was used to compare the mean AIMS scores of the study population with the normative values of Canadian infants ${ }^{5}$ for each group. Statistical significance was accepted as $\mathrm{p}<0.05$.

\section{Results}

The study consisted of 411 full-term infants whose gestational age ranged between 38 
and 42 weeks. The demographic and clinical characteristics of infants are shown in Table I. Table II and Figure 1 provide information about the percentiles of Turkish full-term infants by age groups.

Table III presents the means and standard deviations of the AIMS scores of Turkish and Canadian infants, and a comparison of mean AIMS scores of Turkish infants and the original Canadian scores for 0 to 18 months according to age groups. In general, the original Canadian scores were higher compared with the scores of Turkish infants across several age groups. Statistically significant differences were observed between Turkish and Canadian infants only at $0-<1(p=0.025)$ and $2-<3(p=0.042)$ months of age, and there were no statistically significant differences for any other age groups.

\section{Discussion}

The main purpose of the present study was to provide the preliminary results of AIMS

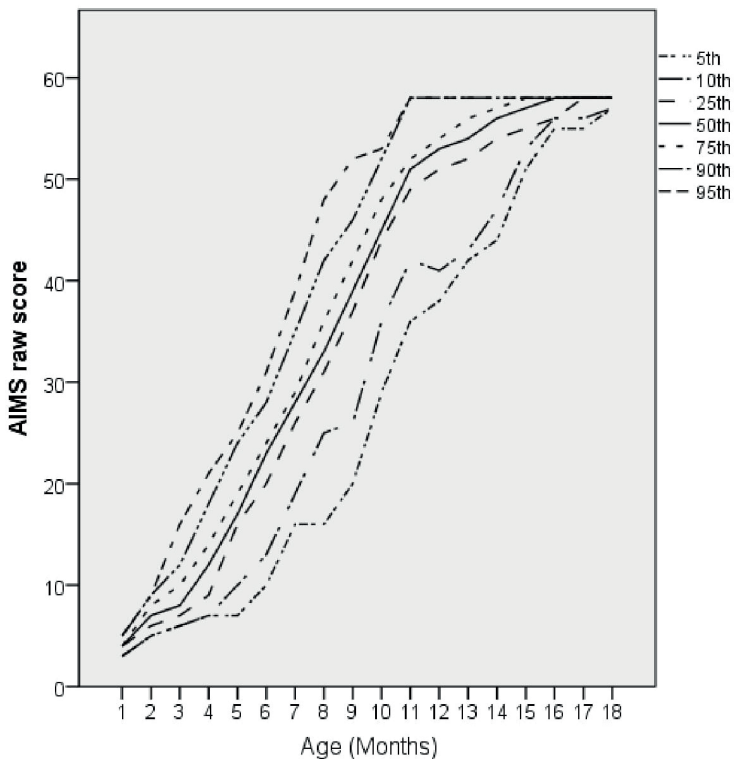

Fig. 1. Percentile ranks of AIMS-scores in Turkish infants.

scores in a cohort of Turkish infants. The AIMS scores of the infants included in this study were compared with the original Canadian norms. ${ }^{5}$ As a result, the AIMS scores of the Turkish and

Table II. The percentile ranks of AIMS scores of Turkish full-term infants.

\begin{tabular}{|c|c|c|c|c|c|c|c|c|}
\hline \multirow{2}{*}{ Age (months) } & \multirow{2}{*}{$\mathrm{n}$} & \multicolumn{7}{|c|}{ Percentile ranks } \\
\hline & & 5 th & 10th & 25th & 50th & 75th & 90th & 95th \\
\hline $0-<1$ & 21 & 3 & 3 & 4 & 4 & 4 & 5 & 5 \\
\hline $1-<2$ & 39 & 5 & 5 & 6 & 7 & 8 & 9 & 9 \\
\hline $2-<3$ & 32 & 6 & 6 & 7 & 8 & 10 & 12 & 16 \\
\hline $3-<4$ & 23 & 7 & 7 & 9 & 12 & 14 & 18 & 21 \\
\hline $4-<5$ & 20 & 7 & 10 & 16 & 17 & 19 & 24 & 25 \\
\hline $5-<6$ & 23 & 10 & 13 & 20 & 23 & 24 & 28 & 31 \\
\hline $6-<7$ & 20 & 16 & 19 & 26 & 28 & 29 & 35 & 39 \\
\hline $7-<8$ & 20 & 16 & 25 & 31 & 33 & 36 & 42 & 48 \\
\hline $8-<9$ & 25 & 20 & 26 & 37 & 39 & 42 & 46 & 52 \\
\hline $9-<10$ & 21 & 29 & 36 & 44 & 45 & 48 & 52 & 53 \\
\hline $10-<11$ & 22 & 36 & 42 & 49 & 51 & 52 & 58 & 58 \\
\hline $11-<12$ & 20 & 38 & 41 & 51 & 53 & 54 & 58 & 58 \\
\hline $12-<13$ & 21 & 42 & 43 & 52 & 54 & 56 & 58 & 58 \\
\hline $13-<14$ & 20 & 44 & 47 & 54 & 56 & 57 & 58 & 58 \\
\hline $14-<15$ & 22 & 51 & 53 & 55 & 57 & 58 & 58 & 58 \\
\hline $15-<16$ & 20 & 55 & 56 & 56 & 58 & 58 & 58 & 58 \\
\hline $16-<17$ & 22 & 55 & 56 & 58 & 58 & 58 & 58 & 58 \\
\hline $17-<18$ & 20 & 57 & 57 & 58 & 58 & 58 & 58 & 58 \\
\hline
\end{tabular}


Table III. Comparison of the mean-AIMS scores of Turkish and Canadian infants.

\begin{tabular}{|c|c|c|c|c|c|c|c|c|c|c|}
\hline \multirow{2}{*}{ Age (months) } & \multicolumn{4}{|c|}{ Turkish infants } & \multicolumn{4}{|c|}{ Canadian infants* } & \multirow{2}{*}{$\mathrm{M}_{\mathrm{T}}-\mathrm{M}_{\mathrm{C}}$} & \multirow{2}{*}{$\mathrm{p}$} \\
\hline & $\mathrm{n}$ & girls/boys & $\mathrm{M}_{\mathrm{T}}$ & $\mathrm{SD}$ & $\mathrm{n}$ & girls/boys & $\mathrm{M}_{\mathrm{C}}$ & SD & & \\
\hline $0-<1$ & 21 & $11 / 10$ & 4.1 & 0.76 & 22 & $9 / 23$ & 4.5 & 1.37 & -0.40 & 0.025 \\
\hline $1-<2$ & 39 & $15 / 24$ & 6.97 & 1.38 & 56 & $29 / 27$ & 7.3 & 1.96 & -0.33 & 0.150 \\
\hline $2-<3$ & 32 & $16 / 16$ & 8.78 & 2.72 & 118 & $58 / 60$ & 9.8 & 2.42 & -1.02 & 0.042 \\
\hline $3-<4$ & 23 & $12 / 11$ & 11.96 & 3.74 & 90 & $45 / 45$ & 12.6 & 3.29 & -0.64 & 0.419 \\
\hline $4-<5$ & 20 & $7 / 13$ & 17.15 & 4.1 & 122 & $53 / 69$ & 17.9 & 4.15 & -0.75 & 0.455 \\
\hline $5-<6$ & 23 & $13 / 10$ & 22.04 & 4.92 & 189 & $109 / 80$ & 23.2 & 4.75 & -1.16 & 0.272 \\
\hline $6-<7$ & 20 & $4 / 16$ & 27.45 & 5.24 & 225 & $106 / 119$ & 28.3 & 5.50 & -0.85 & 0.478 \\
\hline $7-<8$ & 20 & $13 / 7$ & 33.05 & 6.54 & 222 & $102 / 120$ & 32.3 & 6.85 & 0.75 & 0.614 \\
\hline $8-<9$ & 25 & $11 / 14$ & 38.36 & 7.15 & 220 & $111 / 109$ & 38.9 & 8.69 & -0.54 & 0.709 \\
\hline $9-<10$ & 21 & $10 / 11$ & 44.71 & 5.5 & 189 & $84 / 105$ & 45.5 & 7.47 & -0.79 & 0.521 \\
\hline $10-<11$ & 22 & $14 / 8$ & 50.14 & 5.21 & 155 & 74/81 & 49.3 & 5.92 & -0.84 & 0.460 \\
\hline $11-<12$ & 20 & $8 / 12$ & 51.8 & 4.94 & 155 & $78 / 77$ & 51.3 & 7.11 & -0.50 & 0.656 \\
\hline $12-<13$ & 21 & $8 / 13$ & 52.95 & 4.58 & 124 & $71 / 53$ & 54.6 & 4.52 & -1.65 & 0.115 \\
\hline $13-<14$ & 20 & $12 / 8$ & 54.75 & 3.75 & 86 & $39 / 47$ & 55.6 & 5.01 & -0.85 & 0.324 \\
\hline $14-<15$ & 22 & $13 / 9$ & 56.27 & 2.02 & 61 & $25 / 36$ & 56.9 & 1.97 & -0.63 & 0.162 \\
\hline $15-<16$ & 20 & $10 / 10$ & 57.4 & 0.99 & 40 & $21 / 19$ & 57.8 & 0.45 & -0.40 & 0.088 \\
\hline $16-<17$ & 22 & $10 / 12$ & 57.64 & 0.84 & 49 & $21 / 28$ & 57.8 & 0.55 & -0.16 & 0.376 \\
\hline $17-<18$ & 20 & $8 / 12$ & 57.85 & 0.36 & 49 & $21 / 28$ & 57.9 & 0.35 & -0.05 & 0.549 \\
\hline
\end{tabular}

$\mathrm{M}_{\mathrm{T}}=$ mean in Turkish infants; $\mathrm{M}_{\mathrm{C}}=$ mean in Canadian infants; $\mathrm{n}$ = number of participants; $\mathrm{SD}$ = standard deviation

*The mean AIMS-scores, n, and SD values of Canadian infant reported as in the AIMS manual (Reference 5: Piper MC,

Darrah J. Motor Assessment of the Developing Infant. Philadelphia: WB Saunders, 1994: 205.)

Canadian infants were similar, except the first and third months of age. Canadian infants seem to have had earlier motor development in the first months than Turkish infants, and they showed higher scores compared with Turkish infants across several age groups, but there was a statistically significant difference only in the first month and third month of age. Especially after the 6th month, AIMS scores were quite similar. To our knowledge, AIMS has not yet been validated in a Turkish population, and the current study is presented as a preliminary study to determine the AIMS scores of Turkish full-term infants.

AIMS is a discriminative scale used to assess gross motor development of children from birth to 18 months of age and provides total raw scores. The scale is performed by observing the spontanous movements of a child in different positions; it is inexpensive, practical, does not require excessive handling of the child, and can be completed in a shorttime. ${ }^{5,9,6}$ Due to these reasons, AIMS has been widely used as a measure of clinical outcomes and research, both in preterm and term infants around the world. ${ }^{9,10,13,18}$ Nevertheless, several studies indicated that AIMS normative data would be inadequate for children of different cultures. ${ }^{11,15,22,27}$ One such study by Fleuren et al. ${ }^{21}$ emphasized that new reference values of AIMS needed to be established for Dutch children, and the authors also suggested that all other European countries needed to determine the need for new reference values. Another study performed by Syrengelas et al. ${ }^{13}$ indicated that Greek infants showed gross motor maturity similar to Canadian infants. In contrast, Darrah et al. ${ }^{20}$, who developed AIMS, demonstrated that AIMS continued to perform remarkably similarly to previous studies. The authors asserted that the current normative values had remained valid for over 20 years and it might not be necessery to investigate ethnic 
or international differences. ${ }^{20}$ It is important to note that the sample of this research published in 2014, consisted of Canadian infants, and it is not possible to compare the sample directly with international populations. However, it is clear that the original scores of AIMS should be used as they have been in the past. ${ }^{20}$ Conflictingly, in 2016, Saccani et al. ${ }^{11}$ found that the AIMS scores of Brazilian and Canadian infants were different, and emphasized the need to create new reference values for AIMS scores of infants for different cultures. The authors also reported that the AIMS scores of Brazilian infants were significantly lower than the original AIMS scores in the first 3 months of life. ${ }^{11}$ The results of another study performed by Syrengelas et al. ${ }^{13}$ showed that Greek infants at 2-<3 months received significantly higher AIMS scores than Canadian infants, but there were no significant differences for the other age levels till 18 months, and the authors attributed these differences to possible variations in childrearing and parental care.

Etnicity, child-rearing practices, and cultural differences could affect the gross motor development of infants. ${ }^{28,29}$ In addition, maternal care including the baby's sleep and play position, the time spent with the child, and the ability to play with toys are also important for the development of the child. ${ }^{11,30,31}$ De Kegel et al. ${ }^{22}$ demonstrated that Flemish infants had lower AIMS scores than the Canadian norms, they also questioned the sleep and play positioning of infants, and postulated that the lower scores of Flemish infants were related to the sleep position and play time in different positions such as in the supine and prone position or in a sitting device. It is known that in some areas in Turkey, babies are swaddled in the early months and / or are not lain in the prone position. As a matter of fact, some babies who were brought to our clinic for a gross motor development assessment were swaddled. The sleep and play positions of the infants may be related to infant gross motor development, and 'tummy time' is an important position for developing the upper body strength in order to achieve movement against gravity. ${ }^{32,33}$ Although the sleep positions of children and also the time they spend on their tummy during awake periods were not known in present study, many parents reported that they had difficulty keeping their infant in the prone position while awake. Therefore, cultural differences such as swaddling, parent's childrearing practices or socio-economic factors may play a role in the gross motor abilities of infants. In addition, although there was no statistically significant difference between the AIMS scores of Turkish and Canadian infants at 2 months of age, Turkish infants showed a lower motor performance than Canadian infants in the same age range. It should be kept in mind that the AIMS scores of Turkish infants were lower than the original AIMS scores in all age groups until the first 5 months of life, and it remains to be investigated as to whether this difference was clinically important or if it was a random result. Hovewer, the gross motor milestones were found similar across five diverse countries, ${ }^{34}$ and another study ${ }^{35}$ found similar results across four countries including Turkey. It has also been reported in studies that environmental or/ and familial factors may adversely affect child development. ${ }^{36,37}$ Saccani et al. ${ }^{27}$ investigated gross motor development of Brazilian, Greek and Canadian infants assessed with AIMS, and reported that in the second year of life differences in the motor development were milder and at 15 months of age were similar in the three groups. Whether the gross motor development domains vary in healthy children across different countries and different factors such as ethnicity, cultural or socio-economic factors has not been established. Further research is needed to make clear whether the AIMS score may be affected by different social, cultural or ethnic factors. This differences in the scores of Turkish and Canadian infants might be due to the fact that there is less movement performance capacity in the first months of life and fewer items can be evaluated in the subcategories. AIMS provides fewer items to assess gross motor development of infants within the first month of life. 
Another issue that should be considered is the opinions about the low sensitivity of AIMS in early life. ${ }^{11,38}$ According to a systematic review, it may be better to use more detailed tests such as the Bayley test or Test of Infant Motor Performance (TIMP) for the first months of life. ${ }^{38}$ Another study indicated that only a few items were suitable for assessing infants in the early months, and evaluations of gross motor development using AIMS from three to nine months of age were best. ${ }^{39}$ In the present study, the differences of AIMS scores between Turkish and Canadian infants in the first months of life may be due to the lack of sensitivity of AIMS.

The main limitation of the present study is that the sample of the study may not reflect the general AIMS scores of Turkish infants because the study was conducted in only one city in Turkey. The fact remains, however, the city from which the data were provided is the most populous metropolis in the country, and receives immigration from every city in the country. When considered from this point of view, the data collected from Istanbul may reflect a large part of the country, but data collected from different areas of the country may be more reliable in order to reach safe conclusions. In addition, the power analysis for this study was calculated on the basis of findings from a previous study ${ }^{13}$ with a 0.05 significance level, which found that 20 subjects for each age group could provide a power of $80 \%$, and the study produced enough data to provide this power. Another limitation is that only one observer assessed all the infants, thus intraand inter-observer consistency could not be evaluated. Finally, the effects of socioeconomic factors on motor development of infants were not investigated.

In conclusion, our findings suggest that AIMS can be used in Turkish children, especially after 4 months of age. However, this paper is presented as a preliminary study to compare AIMS results between Turkish and Canadian infants, and we strongly recommend that a validation study including cultural adaptations and data collected from different areas of the country should be performed in order to draw more reliable conclusions. AIMS can be used as a valuable, easy and functional assessment tool in the early identification of risky infants in maternity hospitals, routine health services or centers that privode early intervention in Turkey, as well as a basis for research studies. However, further studies are needed to determine if AIMS is valid for the greater Turkish infant population in different cities to assess gross motor development and determine developmental delays. In our opinion, one of the future goals should be to realize the Turkish validation of AIMS in a cohort of full-term and also preterm Turkish infants.

\section{Acknowledgements}

The authors thank Mr. David F. Chapman for his editing support.

\section{REFERENCES}

1. Kjølbye CB, Drivsholm TB, Ertmann RK, Lykke K, Køster-Rasmussen R. Motor function tests for 0-2-year-old children - a systematic review. Dan Med J 2018; 65: A5484.

2. Burger M, Louw QA. The predictive validity of general movements - A systematic review. Eur J Paediatr Neurol 2009; 13: 408-420.

3. Song YH, Chang HJ, Shin YB, Park YS, Park YH, Cho ES. The validity of two neuromotor assessments for predicting motor performance at 12 months in preterm infants. Ann Rehabil Med 2018; 42: 296-304.

4. Hoskens J, Klingels K, Smits-Engelsman B. Validity and cross-cultural differences of the Bayley Scales of Infant and Toddler Development, Third Edition in typically developing infants. Early Hum Dev 2018; 125: 17-25.

5. Piper MC, Darrah J. Motor Assessment of the Developing Infant. Philadelphia: WB Saunders, 1994.

6. Darrah J, Piper M, Watt M-J. Assessment of gross motor skills of at-risk infants: predictive validity of the Alberta Infant Motor Scale. Dev Med Child Neurol 1998; 40: 485-491.

7. Piper MC, Pinnell LE, Darrah J, Maguire T, Byrne PJ. Construction and validation of the Alberta Infant Motor Scale (AIMS.) Can J Public Health 1992; 83(Suppl 2): 46-50. 
8. Campbell SK, Kolobe THA, Wright BD, Linacre JM. Validity of the test of infant motor performance for prediction of 6-, 9- and 12-month scores on the Alberta Infant Motor Scale. Dev Med Child Neurol 2002; 44: 263-272.

9. Fuentefria RN, Silveira RC, Procianoy RS. Motor development of preterm infants assessed by the Alberta Infant Motor Scale: systematic review article. J Pediatr (Rio J) 2017; 93: 328-342.

10. de Albuquerque PL, Lemos A, Guerra MQDF, Eickmann SH. Accuracy of the Alberta Infant Motor Scale (AIMS) to detect developmental delay of gross motor skills in preterm infants: a systematic review. Dev Neurorehabil 2015; 18: 15-21.

11. Saccani R, Valentini NC, Pereira KRG. New Brazilian developmental curves and reference values for the Alberta infant motor scale. Infant Behav Dev 2016; 45(Pt A): 38-46.

12. Morales-Monforte E, Bagur-Calafat C, Suc-Lerin N, Fornaguera-Martí M, Cazorla-Sánchez E, GirabentFarrés M. The Spanish version of the Alberta Infant Motor Scale: Validity and reliability analysis. Dev Neurorehabil 2017; 20: 76-82.

13. Syrengelas D, Siahanidou T, Kourlaba G, Kleisiouni P, Bakoula C, Chrousos GP. Standardization of the Alberta infant motor scale in full-term Greek infants: preliminary results. Early Hum Dev 2010; 86: 245249.

14. Manuel AE, Burger M, Louw QA. Validation of the Canadian norms for the Alberta In fant Motor Scale for infants in a South African region aged four to twelve months; a pilot study. South African J Physiother 2012; 68: 23-28.

15. Valentini NC, Saccani R. Brazilian validation of the Alberta Infant Motor Scale. Phys Ther 2012; 92: 440447.

16. Uesugi M, Tokuhisa K, Shimada T. The reliability and validity of the Alberta Infant Motor Scale in Japan. J Phys Ther Sci 2008; 20: 169-175.

17. Wang $\mathrm{H}$, Li H, Wang J, Jin H. Reliability and concurrent validity of a Chinese version of the Alberta Infant Motor Scale administered to high-risk infants in China. Biomed Res Int 2018; 2018: 1-10.

18. Jeng SF, Yau KIT, Chen LC, Hsiao SF. Alberta Infant Motor Scale: reliability and validity when used on preterm infants in Taiwan. Phys Ther 2000; 80: 168178.

19. Lee LLS, Harris SR. Psychometric properties and standardization samples of four screening tests for infants and young children: a review. Pediatr Phys Ther 2005; 17: 140-147.
20. Darrah J, Bartlett D, Maguire TO, Avison WR, Lacaze-Masmonteil T. Have infant gross motor abilities changed in 20 years? A re-evaluation of the Alberta Infant Motor Scale normative values. Dev Med Child Neurol 2014; 56: 877-881.

21. Fleuren KMW, Smit LS, Stijnen T, Hartman A. New reference values for the Alberta Infant Motor Scale need to be established. Acta Paediatr 2007; 96: 424427.

22. De Kegel A, Peersman W, Onderbeke K, Baetens T, Dhooge I, Van Waelvelde H. New reference values must be established for the Alberta Infant Motor Scales for accurate identification of infants at risk for motor developmental delay in Flanders. Child Care Health Dev 2013; 39: 260-267.

23. Elbasan B, Kocyigit MF, Soysal-Acar AS, Atalay Y, Gucuyener K. The effects of family-centered physiotherapy on the cognitive and motor performance in premature infants. Infant Behav Dev 2017; 49: 214-219.

24. Hosbay Yildirim Z, Aydinli N, Ekici B, Tatli B, Caliskan M. Can Alberta Infant Motor Scale and Milani Comparetti Motor Development Screening Test be rapid alternatives to Bayley scales of infant development-II at high-risk infants. Ann Indian Acad Neurol 2012; 15: 196-199.

25. Blanchard Y, Neilan E, Busanich J, Garavuso L, Klimas D. Interrater reliability of early intervention providers scoring the Alberta Infant Motor Scale. Pediatr Phys Ther 2004; 16: 13-18.

26. Faul F, Erdfelder E, Lang AG, Buchner A. G*Power 3: a flexible statistical power analysis program for the social, behavioral, and biomedical sciences. Behav Res Methods 2007; 39: 175-191.

27. Saccani R, Valentini NC. Cross-cultural analysis of the motor development of Brazilian, Greek and Canadian infants assessed with the Alberta Infant Motor Scale. Rev Paul Pediatr 2013; 31: 350-358.

28. Kelly Y, Sacker A, Schoon I, Nazroo J. Ethnic differences in achievement of developmental milestones by 9 months of age: the Millennium Cohort Study. Dev Med Child Neurol 2006; 48: 825830.

29. Adolph KE. Learning to move. Curr Dir Psychol Sci 2008; 17: 213-218.

30. Hamadani JD, Tofail H, Hilaly A, Huda SN, Engle P, Grantham-McGregor SM. Use of family care indicators and their relationship with child development in Bangladesh. J Health Popul Nutr 2010; 28: 23-33.

31. Bartlett DJ, Kneale-Fanning JE. Relationships of equipment use and play positions to motor development at eight months corrected age of infants born preterm. Pediatr Phys Ther 2003; 15: 8-15. 
32. Koren A, Reece SM, Kahn-D'angelo L, Medeiros D. Parental information and behaviors and provider practices related to tummy time and back to sleep. J Pediatr Heal Care 2010; 24: 222-230.

33. Sals JS, Silverman LN, Gatty CM. The relationship of infant sleep and play positioning to motor milestone achievement. Am J Occup Ther 2002; 56: 577-580.

34. WHO Multicentre Growth Reference Study Group. Assessment of sex differences and heterogeneity in motor milestone attainment among populations in the WHO Multicentre Growth Reference Study. Acta Paediatr Suppl 2006; 450: 66-75.

35. Ertem IO, Krishnamurthy V, Mulaudzi MC, et al. Similarities and differences in child development from birth to age 3 years by sex and across four countries: a cross-sectional, observational study. Lancet Glob Health 2018; 6: e279-e291.
36. da Rocha Neves K, de Souza Morais RL, Teixeira RA, Pinto PAF. Growth and development and their environmental and biological determinants. J Pediatr (Rio J) 2016; 92: 241-250.

37. Walker SP, Wachs TD, Gardner JM, et al; International Child Development Steering Group. Child development: risk factors for adverse outcomes in developing countries. Lancet 2007; 369: 145-157.

38. Spittle AJ, Doyle LW, Boyd RN. A systematic review of the clinimetric properties of neuromotor assessments for preterm infants during the first year of life. Dev Med Child Neurol 2008; 50: 254-266.

39. Liao PJM, Campbell SK. Examination of the item structure of the Alberta Infant Motor Scale. Pediatr Phys Ther 2004; 16: 31-38. 